\title{
NAMPT (visfatin) in the chicken testis: influence of sexual maturation on cellular localization, plasma levels and gene and protein expression
}

\author{
Olga M Ocón-Grove, Susan M Krzysik-Walker, Sreenivasa R Maddineni, Gilbert L Hendricks III \\ and Ramesh Ramachandran \\ Department of Poultry Science, Center for Reproductive Biology and Health, The Pennsylvania State University, \\ 213 Henning Building, University Park, Pennsylvania 16802, USA
}

Correspondence should be addressed to R Ramachandran; Email: rameshr@psu.edu

O M Ocón-Grove and S M Krzysik-Walker contributed equally to this work

\begin{abstract}
Nicotinamide phosphoribosyltransferase (NAMPT) is a cytokine hormone and rate-limiting enzyme involved in production of NAD and therefore affects a variety of cellular functions requiring NAD. Spermatogenesis and testicular steroidogenesis are likely to depend on NAD-dependent reactions and may therefore be affected by changes in testicular NAMPT expression. The objectives of the present study are to investigate testicular NAMPT expression as well as plasma NAMPT levels in prepubertal and adult chickens. By RT-PCR, NAMPT cDNA expression was detected in prepubertal and adult chicken testes. Using immunohistochemistry, NAMPT was predominantly localized in the nucleus of myoid cells, Sertoli cells, and Leydig cells in the prepubertal chicken testis. In adult chickens, however, NAMPT-immunostaining was observed in the cytoplasm of Leydig cells, Sertoli cells, primary spermatocytes, secondary spermatocytes, round spermatids, and elongated spermatids, but not in the spermatogonial cells. Using real-time quantitative PCR, adult chicken testis was found to contain fourfold greater NAMPT mRNA quantity compared with prepubertal chickens. Testicular NAMPT protein quantities determined by western blotting were not significantly different between adult and prepubertal chicken testes. Using immunoblotting, NAMPT was detected in the seminal plasma and sperm protein extracts obtained from chicken semen. Plasma NAMPT levels, determined by enzyme immunoassay, were at least 28-fold higher in the adult chickens compared with prepubertal male chickens. Taken together, sexual maturation is associated with several changes in testicular NAMPT expression indicating that NAMPT is likely to play a significant role in testicular functions such as spermatogenesis and steroidogenesis.
\end{abstract}

Reproduction (2010) 139 217-226

\section{Introduction}

Nicotinamide phosphoribosyltransferase (NAMPT, also known as visfatin) a cytokine hormone and an enzyme, has recently received much attention due to its potential role in obesity, dyslipidemia, type II diabetes mellitus, and immune disorders (Chen et al. 2006, Haider et al. 2006, Brentano et al. 2007, Varma et al. 2007). Originally identified 40 years ago as NAMPT (Dietrich et al. 1966, Powanda et al. 1969, Streffer \& Benes 1971), it was found to act as an intracellular enzyme that catalyzes the rate-limiting conversion of nicotinamide to nicotinamide mononucleotide (NMN), a substrate in the biosynthesis of NAD. Several years later, the peptide was rediscovered as pre-B cell colony-enhancing factor, a presumptive cytokine that enhances maturation of B-lymphocyte precursors in the presence of interlukin7 and stem cell factor (Samal et al. 1994). Although lacking a signal peptide, NAMPT is believed to be secreted in an as yet uncharacterized pathway (Tanaka et al. 2007), and has been detected in both milk (Yonezawa et al. 2006) and in blood circulation. Elevated plasma NAMPT levels have been associated with a variety of conditions including type II diabetes (Chen et al. 2006, Yilmaz et al. 2008) and polycystic ovarian syndrome (Chan et al. 2007). The biologically active form of NAMPT appears to be essential for life, as homozygous mice carrying a mutant NAMPT allele are embryonic lethal at day 10.5 (Revollo et al. 2007). Conversely, haplodeficiency of the NAMPT gene in female mice resulted in defects in NAD biosynthesis and glucosestimulated insulin secretion from pancreatic islets due to a decrease in both intracellular and plasma NAMPT levels (Revollo et al. 2007). Interestingly, these results were sex specific, as such a decrease in NAMPT levels were not observed in the male $N A M P T^{+/-}$mice (Revollo et al. 2007). While previous studies have 
shown NAMPT expression in a variety of tissues including testes (Rongvaux et al. 2002, Revollo et al. 2007), the possible contribution of testicular NAMPT has not yet been explored.

Recently, we have shown that chicken NAMPT cDNA and protein are highly homologous to mammalian NAMPT (Krzysik-Walker et al. 2008). In addition, NAMPT protein levels were elevated with age in the skeletal muscle and plasma of male chickens. Similar to mammalian NAMPT expression, our preliminary studies indicated that NAMPT is ubiquitously expressed in various tissues of the chicken, including the testes. In order to further characterize testicular NAMPT expression during sexual maturation, broiler breeder male chickens were utilized for the current study. Broiler breeder males are genetically selected for production of rapidly growing progenies that are able to attain a 40-fold increase in body weight within 42 days posthatch. Consequently, broiler breeder chickens are an excellent model to study the influence of NAMPT, a molecule that is important for energy metabolism, on testicular function. During sexual maturation, we presume that NAD biosynthesis would be vital to support spermatogenesis and produce energy to enable sperm survival and mobility. Therefore, based on the role of NAMPT in NAD biosynthesis, we hypothesized that testicular NAMPT expression would increase when broiler breeder male chickens undergo sexual maturation.

The objectives of the current study were to characterize testicular NAMPT gene and protein expression and determine plasma NAMPT levels in prepubertal and adult chickens. We provide novel evidence that NAMPT gene expression is significantly increased in the testis of adult male chickens compared with prepubertal chickens and is accompanied by a 28-fold increase in plasma NAMPT levels. Furthermore, our data indicate that NAMPT expression within the testis undergoes a dramatic shift from nuclear localization in myoid cells and Leydig cells in prepubertal chickens to cytoplasmic localization in primary spermatocytes, Sertoli cells, Leydig cells, and postmeiotic cells within the seminiferous tubules of adult chicken testis. We also present evidence that NAMPT is detectable in seminal plasma and sperm protein extracts, suggesting that NAMPT could play an important role in sperm physiology.

\section{Results}

\section{Detection of NAMPT cDNA in testis by RT-PCR}

A 309-bp partial cDNA encoding NAMPT was amplified from total RNA extracted from prepubertal (4- or 14-week-old) and adult (29-week-old) chickens (Fig. 1). The nucleotide sequence of the resultant product was found to be identical to that of NAMPT cDNA

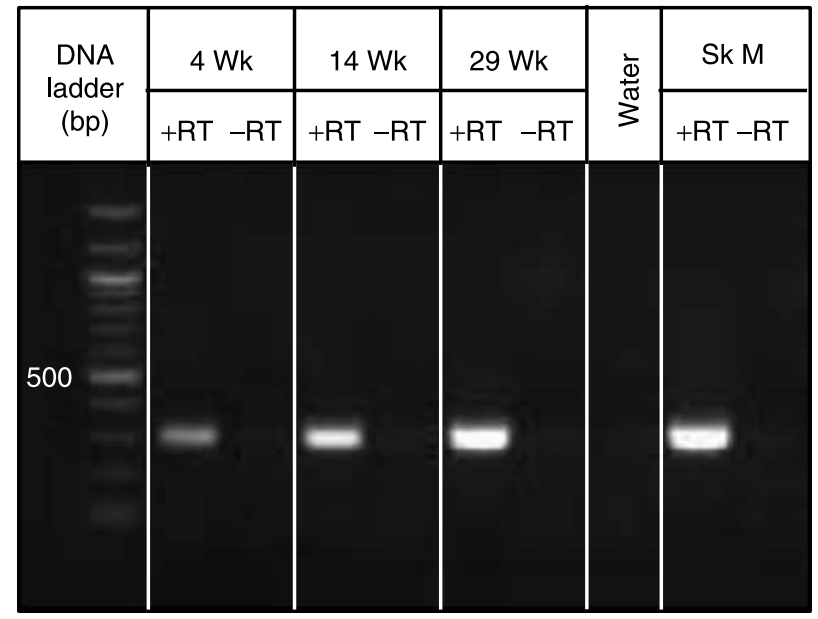

Figure 1 RT-PCR analysis of NAMPT gene expression in the testes of prepubertal and adult chickens. Total RNA was extracted, DNase-I digested, and RT (+RT). Approximately $50 \mathrm{ng}$ of cDNA was used as template to amplify a 309-bp chicken NAMPT cDNA. Skeletal muscle cDNA was included as a positive control. Contamination controls consisted of RNA from each tissue without RT addition ( - RT) or substitution of water for the cDNA template. $4 \mathrm{Wk}$, 4-week-old prepubertal chicken; $14 \mathrm{Wk}$, 14-week-old prepubertal chicken; $29 \mathrm{Wk}$, 29-week-old adult chicken, Sk M, skeletal muscle.

expressed in chicken adipose and skeletal muscle. Furthermore, a 1482-bp full-length NAMPT cDNA was also amplified from the chicken testis (data not shown). The use of either water in place of cDNA template or cDNA that was not reverse transcribed did not produce any PCR product (Fig. 1), confirming the absence of genomic DNA contamination.

\section{Localization of NAMPT-immunoreactive cells in the testis of prepubertal and adult chickens}

Prepubertal (14-week-old) chicken testis

NAMPT immunolabeling within the prepubertal chicken testis is shown in Fig. 2A-D. Around the seminiferous tubules, NAMPT immunostaining was found in the myoid cells that appeared flattened (Fig. 2A, C and D). In addition, several cells in the interstitial space revealed NAMPT immunostaining in the nucleus, possibly representing Leydig cells (Fig. 2A and D). Within the seminiferous tubules, NAMPT immunostaining was found in the nucleus of Sertoli cells and primary spermatocytes (Fig. 2A and C). Preadsorption of the NAMPT antibody with the immunogen greatly reduced or completely abolished NAMPT immunostaining in the prepubertal chicken testis indicating that the immunostaining was specific (Fig. 2B).

\section{Adult (29-week-old) chicken testis}

NAMPT immunostaining within the adult chicken testis is shown in Fig. 3A-I. NAMPT-immunostained cells 

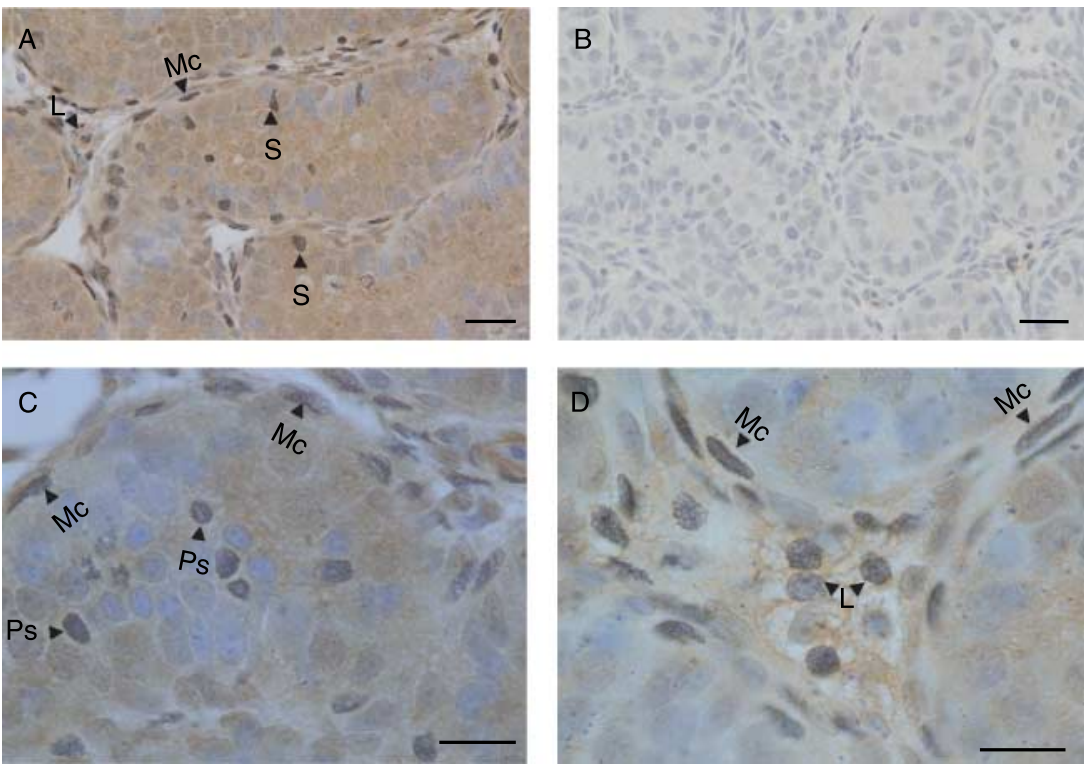

Figure 2 (A-D) Representative photomicrographs of testicular tissue sections from prepubertal chickens showing NAMPT-immunostained cells. Testicular tissue sections were immunostained using anti-human NAMPT antibody and counterstained with hematoxylin. (A, C, and D) NAMPT-immunostaining in the nuclei of myoid cells (Mc), Sertoli cells (S), primary spermatocytes (Ps), and Leydig cells (L). (B) Negative control using preadsorbed antibody in place of primary antibody. Scale bar, $20 \mu \mathrm{m}$. were predominantly observed in the seminiferous tubular adluminal and luminal compartments as well as in the interstitium (Fig. 3A, C, D and F). In contrast to the prepubertal chicken testis, NAMPT immunostaining was noticed in the cytoplasm but not in the nucleus (Fig. 3G-I). In addition, NAMPT immunostaining was not observed in the peritubular myoid cells or in the spermatogonial cells (Fig. 3C, E and G). However, NAMPT immunostaining was noticed in the cytoplasm of primary spermatocytes (Fig. 3G and $\mathrm{H}$ ), secondary spermatocytes (Fig. 3G and I), round spermatids (Fig. 3D, F and G), and elongated spermatids (Fig. 3D, $G$ and I). Intense NAMPT immunostaining was observed in the seminiferous tubular lumen (Fig. 3F), which is likely to be part of Sertoli cell syncytia and/or spermatozoa. Leydig cells in the interstitium (Fig. 3C) and Sertoli cell cytoplasm in the adluminal compartment (Fig. 3C and D) exhibited strong NAMPT immunostaining. This pattern of NAMPT immunostaining was similar in seminiferous tubules of different development stages within the adult chicken testis. Preadsorption of the NAMPT antibody with the immunogen greatly reduced or completely abolished staining indicating that the immunostaining was specific in the adult chicken testis (Fig. 3B).

\section{Relative quantity of testicular NAMPT mRNA by real-time quantitative PCR}

Testicular NAMPT mRNA quantity was significantly greater in adult chickens compared with prepubertal chickens (Fig. 4; $P<0.01$ ). Melting curve analyses showed the presence of a single PCR product for NAMPT mRNA or $18 \mathrm{~S}$ mRNA, confirming the specificity of the reactions (data not shown).

\section{Detection and quantification of testicular NAMPT protein from prepubertal and adult chickens}

In order to detect NAMPT protein in the chicken testis and determine whether NAMPT protein quantity is different between prepubertal and adult chicken testes, a western blot analysis was performed. Our previous study had established the specificity of an anti-human NAMPT antibody to detect chicken NAMPT (Krzysik-Walker et al. 2008). A 52-kDa NAMPT protein was detected in the protein extracts obtained from both prepubertal (14-weekold) and adult (29-week-old) chicken testes (Fig. 5A). The molecular weight of testicular NAMPT protein was identical to that expressed in chicken skeletal muscle, adipose tissue, and liver (Krzysik-Walker et al. 2008). NAMPT protein quantity relative to ACTB quantity was not significantly different between prepubertal and adult chicken testes (Fig. 5B; $P>0.05$ ). Similar to testicular protein, a 52-kDa NAMPT protein was detected in the seminal plasma and sperm protein extracts obtained from chicken semen (Fig. 6). In addition, we observed a lower molecular weight $(\sim 28 \mathrm{kDa})$ NAMPT protein in both sperm protein extract and in seminal plasma. Chicken adipose and liver protein extracts contained a similar 28-kDa NAMPT protein (Krzysik-Walker et al. 2008), which may have resulted from proteolytic degradation (Samal et al. 1994) or due to alternative splicing, as tissuespecific visfatin splice variants have been previously reported in the pig (Chen et al. 2007).

\section{Quantification of plasma NAMPT levels in prepubertal and adult chickens}

In order to determine whether sexual maturation affects plasma NAMPT levels, we quantified plasma NAMPT in prepubertal (4- and 14-week-old) and adult 
(29-week-old) chickens. Plasma collected from adult chickens contained significantly greater levels of NAMPT when compared with that of prepubertal chicken plasma (Fig. 7; $P<0.02$ ). The intra-assay coefficient of variation (CV) was found to be $13.85 \%$ using pooled chicken plasma as reference standard.
The same reference standard yielded an intra-assay CV of $6.46 \%$ in a previous study (Krzysik-Walker et al. 2008). However, the greater intra-assay CV observed in the present study should not affect our interpretation as the plasma visfatin levels were higher by 28 -fold in adult chickens compared with that of prepubertal chickens.
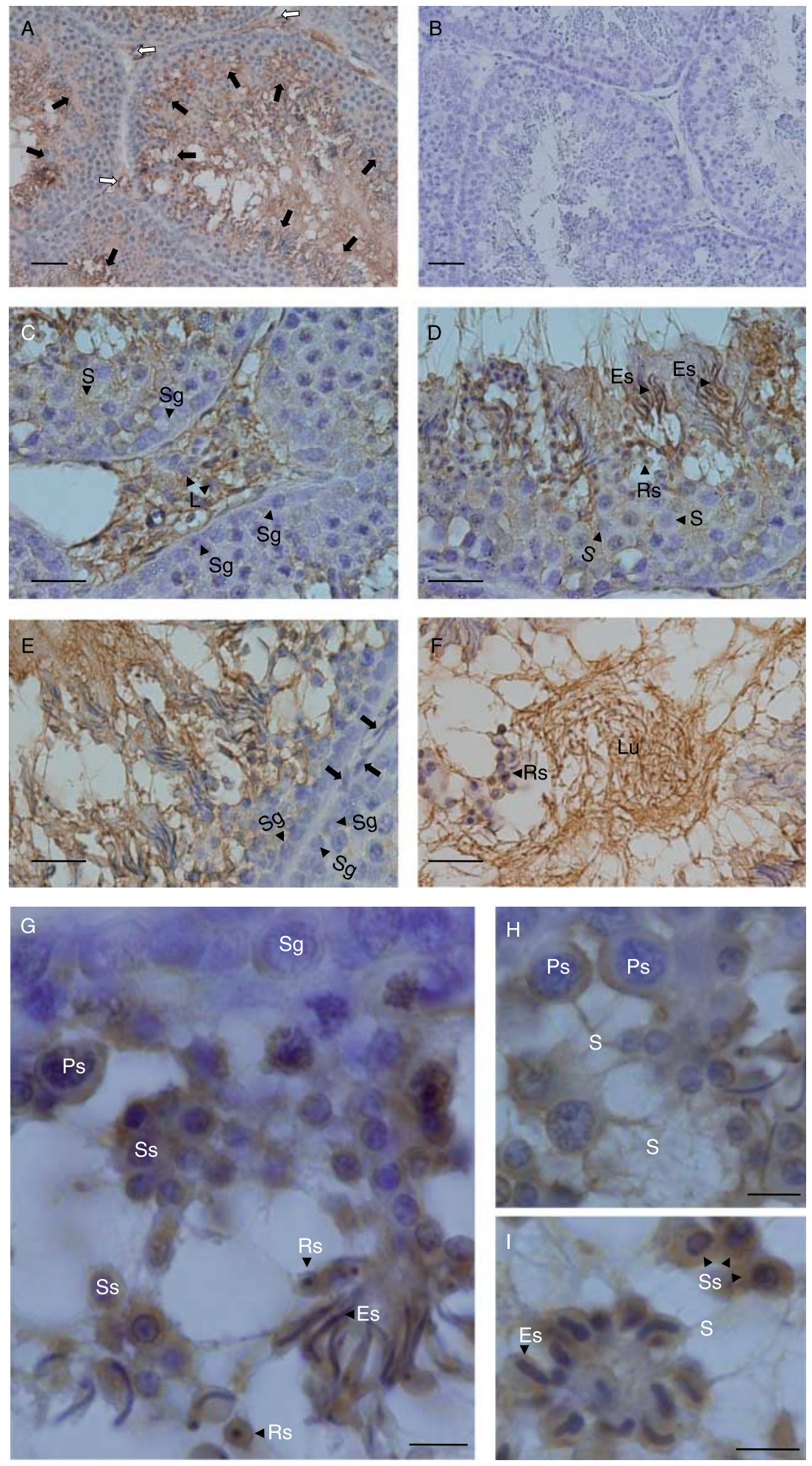

Figure 3 (A-I) Representative photomicrographs of testicular tissue sections from adult chickens showing NAMPT immunostaining. Testicular tissue sections were immunostained using anti-human NAMPT antibody and counterstained with hematoxylin. Seminiferous tubules showing NAMPT immunostaining (black arrows) in the proluminal compartment and in the interstitium (white arrows) (A). NAMPT immunostaining was observed in Sertoli cells (S; C, D, H and I), Leydig cells $(\mathrm{L} ; \mathrm{C})$, primary spermatocytes (Ps; $\mathrm{G}$ and $\mathrm{H})$, secondary spermatocytes (Ss; G and I), round spermatids (Rs; $D, F$ and $G$ ), and elongated spermatids (Es; D, G and I). Seminiferous tubular lumen (Lu; F) showed intense NAMPT immunolabeling representing Sertoli cell syncytia and/or spermatozoa. Negative control using preadsorbed antibody in place of primary antibody showed no specific immunostaining (B). NAMPT immunostaining was not observed in spermatogonial cells (Sg; C, E and G) or in myoid cells (black arrows; E). Scale bar: $20 \mu \mathrm{m}(\mathrm{A}-\mathrm{F}) ; 10 \mu \mathrm{m}(\mathrm{G}-\mathrm{I})$. 


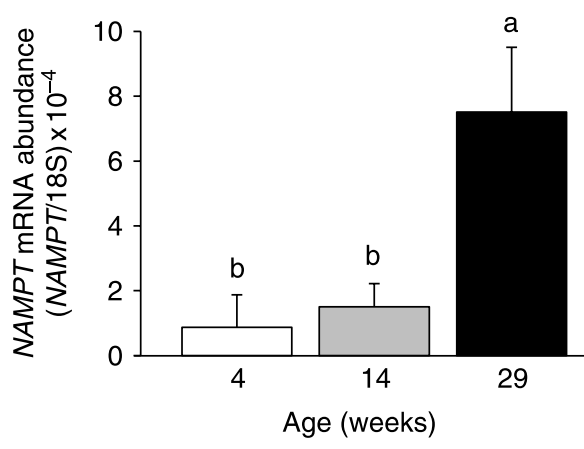

Figure 4 NAMPT mRNA abundance relative to $18 \mathrm{~S}$ mRNA in prepubertal and adult chicken testes. Total RNA from prepubertal (4- or 14-week-old) and adult (29-week-old) chicken testis was extracted, DNase-I digested, and reverse transcribed. Approximately $50 \mathrm{ng}$ of cDNA was used in real-time quantitative PCR. Data are represented as mean \pm S.E.M. Different letters above each bar indicate significant difference at $P<0.05$ ( $n=4-6$ /age group).

\section{Discussion}

The present study is the first to characterize NAMPT expression within the testis of avian species. We provide novel evidence to suggest that testicular NAMPT expression and plasma NAMPT levels significantly increase as the chicken becomes sexually mature. Using RT-PCR and western blot analysis, we found that NAMPT is expressed in the prepubertal and adult chicken testis. This is consistent with previous reports on the detection of NAMPT in the testis of pigs (Chen et al. 2007) and mice (Revollo et al. 2007).

The present study suggests that the subcellular localization of NAMPT varied with sexual maturation in the chicken testis. This shift in NAMPT subcellular localization with sexual maturation may reflect either the metabolic or proliferative state of the cells. A previous study had observed that NAMPT was localized to the nucleus of nondividing PC-12 cells, while subcellular NAMPT localization was found in the cytoplasm of proliferating PC-12 cells (Kitani et al. 2003). In addition to altered subcellular localization, expression of NAMPT in myoid cells was influenced by sexual maturation. NAMPT gene expression appears to be mechanically sensitive in amniotic epithelial cells, with expression increasing in response to acute stretching (Nemeth et al. 2000, Ognjanovic et al. 2005). Furthermore, stretching-induced NAMPT expression protected the amniotic epithelial cells from apoptosis (Kendal-Wright et al. 2008). Based on these findings, we hypothesize that the expanding seminiferous tubules in adult testis may have compressed the myoid cells and led to the absence of NAMPT expression in these cells.

A physiological role of testicular NAMPT is currently unknown in any species. Previous studies have shown that NAMPT is a rate-limiting enzyme in the biosynthesis of NAD (Revollo et al. 2004). Therefore, NAMPT expression in the testicular cells may augment NAD production from nicotinamide, which is then used to support the heightened metabolic activity of Sertoli cells and postmeiotic cells. In addition, NAD is an essential cofactor for the activity of a group of deacetylases called sirtuins (SIRT). In mouse fibroblasts, NAMPT treatment lead to a dose-dependent increase in both cellular NAD levels as well as SIRT1 expression (Revollo et al. 2004). SIRT1 itself appears to be an important enzyme for testicular function as SIRT1 deficiency has been found to attenuate spermatogenesis and germ cell function in mice (Coussens et al. 2008). Moreover, male Sirt $1^{-1-}$ knockout mice had increased proportion of mature sperm with elevated DNA damage, while a microarray analysis of SIRT1-deficient testis revealed dysregulated expression of 85 genes that are involved in spermatogenesis and protein sumoylation (Coussens et al. 2008). In addition to increasing NAD production, NAMPT has been found to increase expression of vascular endothelial growth factor (VEGFA) and VEGFA receptor-2 in vascular endothelial cells through activation of the MAP kinase (MAPK1) and phosphatidylinositol-3-kinase/ AKT1 pathways (Adya et al. 2008). VEGF increases

A

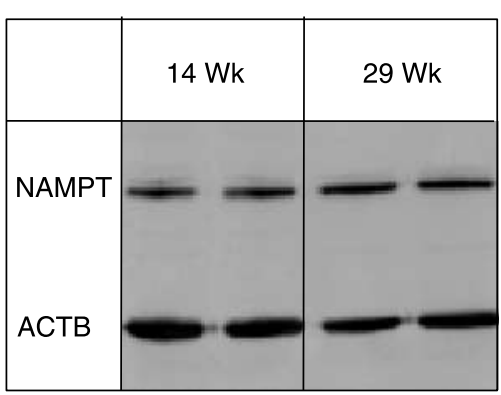

B

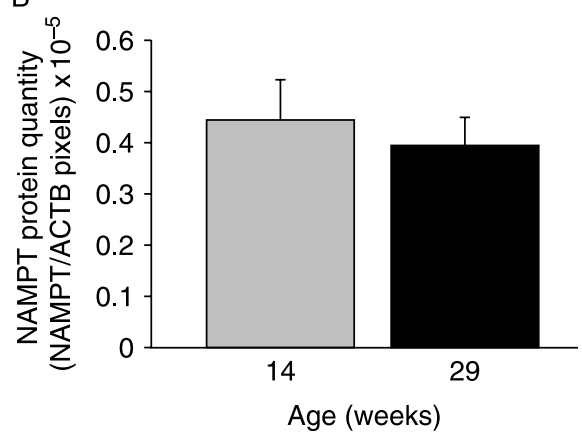

Figure 5 ( $A$ and $B$ ) Detection and quantification of NAMPT protein in the prepubertal and adult chicken testis. (A) Representative blot from two prepubertal (14-week-old) and two adult (29-week-old) chicken testes showing NAMPT and ACTB immunostaining. Approximately $10 \mu \mathrm{g}$ of total protein extract from each testis was electrophoresed and blotted onto PVDF membrane. NAMPT was detected by sequential immunostaining using a rabbit anti-human NAMPT antibody and mouse anti-chicken ACTB antibody. (B) Quantity of NAMPT protein relative to ACTB in prepubertal (14-week-old) and adult (29-week-old). Densitometric data are represented as mean \pm S.E.M. ( $n=5$ /age group). 


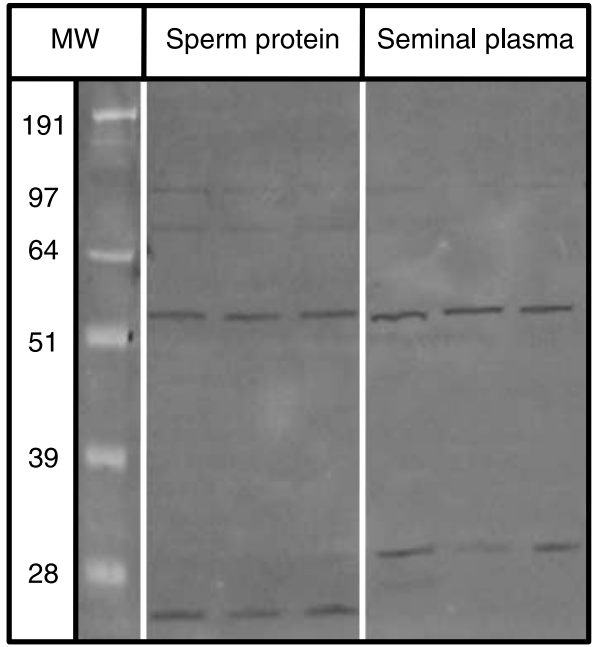

Figure 6 Detection of NAMPT protein in chicken sperm cell protein extract and seminal plasma. Sperm cells and seminal plasma from semen ejaculates from three breeder chickens were separated by centrifugation. Approximately $20 \mu \mathrm{g}$ of total protein from seminal plasma or sperm protein extract from each chicken was electrophoresed and blotted onto PVDF membrane. NAMPT was detected by immunostaining using a rabbit anti-human NAMPT antibody.

vascular endothelial cell proliferation in the testis (Rudolfsson et al. 2004) and can therefore affect testicular vascularization. VEGF expression has been detected in mouse Sertoli cells, whereas its receptors are located in spermatocytes and spermatids (Nalbandian et al. 2003). Hypoxia increases testosterone release in the mouse TM3 cell line mediated by increased VEGFA production (Hwang et al. 2007). Interestingly, hypoxia leads to an increase in NAMPT gene expression in adipocytes and in a breast cancer cell line (Bae et al. 2006, Segawa et al. 2006). Collectively, it appears that NAMPT can play a major role in testicular cellular metabolism, vascularization, and in Sertoli cell and Leydig cell functions.

The present study found that plasma NAMPT levels were 28-fold higher in adult chickens compared with prepubertal chickens. This elevated plasma NAMPT in the adult chicken may be due to several factors such as body weight, muscle mass, age, hormones associated with sexual maturation, and/or chronic feed/calorie restriction. For optimal reproductive performance, the broiler breeder males used in this study were provided with a restricted amount of feed ( $2 \mathrm{~h}$ of feeding to an equivalent of 350 calories per day) according to the feeding schedule recommended by the breeder company (Longnecker Hatcheries, Elizabethtown, PA, USA). In a previous study, plasma NAMPT levels did not change in 8-week-old broiler chickens that were fasted for $48 \mathrm{~h}$ (Krzysik-Walker et al. 2008). However, 48-h fasting did appear to increase NAMPT expression in the rat, suggesting that NAMPT is functioning as a stress- and nutrient-sensitive molecule (Yang et al. 2007). While the NAMPT protein lacks a cleavable signal peptide and is thought to be released from cells by a nonclassical pathway (Tanaka et al. 2007), the source and function of circulating NAMPT are still unknown. Nonetheless, the NAMPT activity of NAMPT may catalyze NAD synthesis from nicotinamide in the blood circulation, and produce precursors that are then available for cellular uptake and homeostasis of intracellular NAD levels (Billington et al. 2008). Indeed, one such precursor, NMN, has been detected in the blood circulation and extracellular fluid of mice (Revollo et al. 2007).

We found that testicular NAMPT mRNA quantity was fourfold greater in adult chickens compared with prepubertal chickens. Testicular NAMPT protein quantity, however, was not different between adult and prepubertal chickens. Such a discordance in NAMPT protein versus mRNA quantity may be due to several factors, such as lack of translation of NAMPT mRNA, rapid turnover of NAMPT protein, and/or a change in localization of NAMPT in myoid cells to germ cells within the seminiferous tubules in the adult testes or secretion of NAMPT. It is also likely that some of the NAMPT mRNA is contained in the sperm that did not undergo translation.

In summary, sexual maturation is associated with an increase in testicular NAMPT expression and circulating NAMPT levels in broiler breeder chickens. Further studies are required to elucidate the role of testicular NAMPT in spermatogenesis and steroidogenesis.

\section{Materials and Methods}

\section{Animals}

Broiler breeder male chickens (Ross strain) were maintained by Longnecker Hatcheries according to the recommended maintenance schedule. Prepubertal (4- and 14-week-old) and adult (29-week-old) male chickens were utilized in this study. Prepubertal chickens were maintained under $8 \mathrm{~h}$ light: $16 \mathrm{~h}$ darkness photoperiod and were provided water and feed

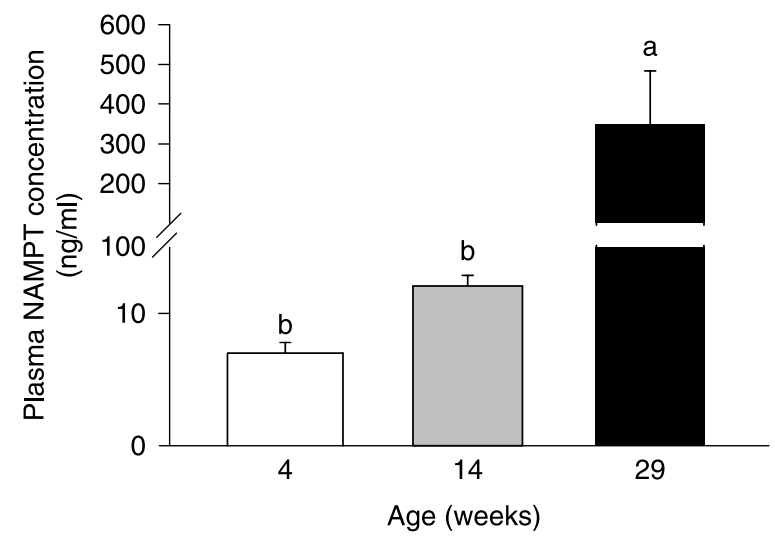

Figure 7 Plasma NAMPT levels in prepubertal (4- or 14-week-old) and adult (29-week-old) as determined by enzyme immunoassay. Different letters above each bar indicate significant difference at $P<0.05$. Data are represented as mean \pm S.E.M. ( $n=6$ /age group). 
ad libitum. Adult chickens (29-week-old) were maintained under $16 \mathrm{~h}$ light: $8 \mathrm{~h}$ darkness photoperiod and provided with water ad libitum but were feed restricted following a feeding program recommended for broiler breeder males (Aviagen, Huntsville, AL, USA). Chickens were killed by cervical dislocation prior to the removal of testis. One testis from each chicken was snap frozen in liquid nitrogen, while the other testis was collected for histological analyses. All animal procedures were carried out in accordance with the Pennsylvania State University Institutional Animal Care and Use Committee.

\section{RNA extraction and $c D N A$ production}

Total RNA was extracted from prepubertal and adult chicken testes ( $n=6$ /age group) using Trizol (Invitrogen) and RNEasy kit (Qiagen) following manufacturer's protocol. The epididymal region was not dissected out of the testes, and therefore, testicular RNA may contain epididymal RNA as well. The quality and quantity of testis total RNA were determined by measuring absorbance at 260 and $280 \mathrm{~nm}$ using a spectrophotometer (ND-1000, NanoDrop, Wilmington, DE, USA). Following on-column DNase-I (Qiagen) treatment, first strand cDNA was synthesized by reverse transcribing $1 \mu \mathrm{g}$ total RNA using random primer 12 and $2 U$ Moloney murine leukemia virus RT (New England Biolabs, Beverly, MA, USA) in $20 \mu \mathrm{l}$ reactions.

\section{RT-PCR analysis}

Approximately $50 \mathrm{ng}$ of single-stranded testis cDNA, or skeletal muscle cDNA as a positive control, was used as template to amplify a 309-bp product of NAMPT with the following primer sequences: forward 5'-CAGGAATAGGAGCTTCAGCCCATTTGGT- $3^{\prime}$ and reverse 5'-GTGCCTCTGGACTTCGGCCTTCAATTAT-3'. A touchdown PCR was performed using $300 \mathrm{mM}$ forward and reverse primers, $300 \mathrm{mM}$ dNTP (Roche Biochemicals), and $1 \mathrm{U}$ Taq polymerase (New England Biolabs) with the following thermocycle parameters: $94{ }^{\circ} \mathrm{C}$ for $1 \mathrm{~min}, 32$ cycles of $94{ }^{\circ} \mathrm{C}$ for $5 \mathrm{~s}$, and $72-68{ }^{\circ} \mathrm{C}$ for $3 \mathrm{~min}$. Annealing and primer extension were done at 72,70 , and $68{ }^{\circ} \mathrm{C}$ during $1-5,6-10$, and $11-32$ cycles respectively. The PCR products were subjected to agarose gel electrophoresis and ethidium bromide staining for visualization. For negative controls, RT reactions using $1 \mu \mathrm{g}$ total RNA from each tissue with no RT ( - RT) or water were used as a template in place of $\mathrm{RT}$ reactions that contained $\mathrm{RT}$ ( $+\mathrm{RT}$ ). The resultant partial NAMPT CDNA, as well as the full-length NAMPT CDNA amplified using primers previously described (Krzysik-Walker et al. 2008), was sequenced (Davis Sequencing, Davis, CA, USA) to confirm authenticity.

\section{Immunohistochemical localization of NAMPT in prepubertal and adult chicken testes}

\section{Tissue preparation}

Prepubertal (14-week-old) and adult (29-week-old) chicken testes ( $n=3$ /age group) were fixed by immersion in fresh $4 \%$ paraformaldehyde for $2-3 \mathrm{~h}$ at room temperature, cut into smaller equal-sized pieces, and fixation continued in $4 \%$ paraformaldehyde at $4{ }^{\circ} \mathrm{C}$ for $\sim 18 \mathrm{~h}$. Testicular pieces were then washed in PBS ( $\mathrm{pH}$ 7.4), dehydrated, cleared, and embedded in paraffin using an automated tissue processor (Thermo Fisher, Kalamazoo, MI, USA). Tissue sections $(4 \mu \mathrm{m})$ were cut using a rotary microtome (Microm, Walldorf, Germany), and serial sections were mounted on Superfrost Plus glass slides (VWR, West Chester, PA, USA).

\section{Immunostaining}

Paraffin tissue sections were deparaffinized in Histoclear (National Diagnostics, Atlanta, GA, USA) and hydrated in descending concentrations of ethyl alcohol in water and rinsed in Tris-buffered saline (TBS; $0.01 \mathrm{M}$ Tris- $\mathrm{HCl}$ and $0.15 \mathrm{M}$ sodium chloride solution, $\mathrm{pH} 7.4$ ). Following several washes in TBS containing 0.1\% Triton X-100 (TBSX; Sigma), slides were treated in a blocking solution $(2 \%$ normal goat serum in TBSX) for $1 \mathrm{~h}$. Slides were incubated with rabbit anti-NAMPT antibody (1:400; Phoenix Pharmaceuticals, Belmont, CA, USA) at $4{ }^{\circ} \mathrm{C}$ for $\sim 18 \mathrm{~h}$. The rabbit antihuman NAMPT antibody used for immunostaining was raised against a 51-amino acid synthetic human NAMPT peptide (amino acid residues between 400 and 450), which is $98.1 \%$ homologous to the corresponding chicken NAMPT sequence. Following washes in TBS, sections were incubated for $1 \mathrm{~h}$ with biotinylated goat anti-rabbit IgG (Vector Laboratories, Burlingame, CA, USA). Tissue sections were washed in TBS and then treated for $1 \mathrm{~h}$ with an avidin peroxidase complex (Vector ABC Elite kit, Vector Laboratories). A brown colored NAMPT immunostain was developed using 3',3'-diaminobenzedine tetrahydrochloride and hydrogen peroxide (Vector Laboratories). After several washes in TBS, tissue sections were lightly counterstained with hematoxylin, dehydrated, cleared in Histoclear, and coverslipped. To determine the specificity of immunostaining, the primary antibody (antihuman NAMPT antibody) was preadsorbed with $25 \mu \mathrm{g} / \mathrm{ml}$ immunogen (51 amino acid synthetic human NAMPT peptide; Bethyl Laboratories, Montgomery, TX, USA) for $18 \mathrm{~h}$ and centrifuged to pellet the antibody-antigen complexes. As a negative control, the supernatant was substituted in place of the primary antibody during immunohistochemical staining. Unless otherwise noted, all steps were performed at room temperature, with wash steps consisting of three ten-minute incubations in TBS buffer. NAMPT-immunostained testicular tissue sections were examined, and photomicrographs were taken using an Olympus BX61 microscope fitted with Olympus DP71 digital camera (Olympus America, Melville, NY, USA).

\section{Determination of NAMPT mRNA quantity by real-time quantitative $P C R$ in prepubertal and adult chicken testes}

Total RNA extracted from prepubertal (4- and 14-week-old) and adult (29-week-old) chicken testes ( $n=4-6 /$ age group) was reverse transcribed using random primers as described above and subjected to real-time quantitative PCR. Chicken NAMPT mRNA and $18 \mathrm{~S}$ mRNA were quantified separately 
utilizing $2.5 \mu \mathrm{l}$ of the RT reaction (equivalent to $50 \mathrm{ng}$ single stranded cDNA) as template. The real-time quantitative PCR consisted of $1 \times$ Platinum SYBR Green qPCR Super Mix-UDG (Invitrogen) and $300 \mathrm{nM}$ of forward and reverse primers containing the following sequences: NAMPT, forward 5'-AGTCCAGAGGCACCACTCAT-3' and reverse 5'-CTGAGATATGGTGGCAGCAA-3', 18S, forward 5'-GTATG GTTGCAAAGCTGAAACTTA- $3^{\prime}$ and reverse $5^{\prime}$-AAGAGCTCTCAATCTGTCAATCCT- $3^{\prime}$. The reactions were carried out in a DNA Engine Opticon II (MJ Research, Reno, NV, USA) with the following thermocycle parameters: $50{ }^{\circ} \mathrm{C}$ for $2 \mathrm{~min}$ (to incubate with uracil DNA glycosylase and prevent amplification of deoxyuracil-containing PCR products), $95^{\circ} \mathrm{C}$ for $2 \mathrm{~min}$, followed by 35 cycles of $95{ }^{\circ} \mathrm{C}$ for $15 \mathrm{~s}, 55^{\circ} \mathrm{C}$ for $30 \mathrm{~s}$, and $72{ }^{\circ} \mathrm{C}$ for $30 \mathrm{~s}$. At the end of amplification, a melting curve analysis was performed by heating the PCR products from 65 to $95^{\circ} \mathrm{C}$, held for $15 \mathrm{~s}$ at increments of $0.2^{\circ} \mathrm{C}$, and fluorescence was detected to confirm the presence of a single amplification product. Samples from each animal were run in duplicate to obtain average log-linear threshold $\left(C_{\mathrm{t}}\right)$ values for NAMPT and 18S mRNA. The log-linear threshold values during the exponential phase of the PCR for NAMPT were subtracted from that of $18 \mathrm{~S}$ mRNA. NAMPT mRNA quantity was expressed as a proportion of $18 \mathrm{~S}$ mRNA quantity. For negative controls, equivalent amounts of RT reactions using $1 \mu \mathrm{g}$ total RNA with no RT were used as template in place of single stranded cDNA in the real-time quantitative PCR.

\section{Quantification of NAMPT protein in prepubertal and adult chicken testes by western blot analysis}

Approximately $0.5 \mathrm{~g}$ of prepubertal (14-week-old) and adult (29-week-old) chicken testes ( $n=5$ /age group) were homogenized using the Tekmar Tissumizer (Tekmar Company, Cincinnati, OH, USA) in $3 \mathrm{ml}$ lysis buffer (10 mM Tris-HCl, $150 \mathrm{mM}$ $\mathrm{NaCl}, \mathrm{pH} 8.0,1 \%$ Nonidet P-40, 0.5\% sodium deoxycholate, $0.1 \%$ SDS), containing protease inhibitor cocktail and phosphatase inhibitor cocktail 2 (Sigma-Aldrich). The homogenate was then passed through a 22-gauge needle and shaken in a thermomixer (Eppendorf, Westbury, NY, USA). The lysate was centrifuged at $14000 \mathrm{~g}$ for $15 \mathrm{~min}$ at $4{ }^{\circ} \mathrm{C}$, and the supernatant was collected. Total protein concentration was estimated by a protein dye-binding assay (Bradford 1976) using a commercial kit (Bio-Rad), with chicken ovalbumin as the standard. Aliquots of testicular protein extracts were stored at $-80{ }^{\circ} \mathrm{C}$ until analyzed by western blotting.

One-dimensional gel electrophoresis was performed with the NuPAGE Novex minigel system (XCell SureLock Mini Cell; Invitrogen) according to manufacturer's recommendations. Samples were prepared by combining $\sim 10 \mu \mathrm{g}$ total protein extract with $4 \times$ NuPAGE LDS sample buffer and $10 \times$ NuPAGE reducing agent, and heated for $10 \mathrm{~min}$ at $70{ }^{\circ} \mathrm{C}$ prior to electrophoresis. Proteins were separated on a $10 \%$ Bis-Tris polyacrylamide gel (Invitrogen) with MOPS running buffer under denaturing conditions for 50-60 min, and electrotransferred onto Immun-Blot PVDF membranes $(0.20 \mu \mathrm{m}$; Bio-Rad) at $30 \mathrm{~V}$ for $60 \mathrm{~min}$ with the XCell II blot module (Invitrogen). Membranes were incubated in blocking buffer $(1 \times$ casein solution; Vector Laboratories) for $2 \mathrm{~h}$ at room temperature, followed by an overnight incubation in rabbit anti-human NAMPT antibody (1:15000 in blocking buffer; Bethyl Laboratories) at $4{ }^{\circ} \mathrm{C}$ with gentle agitation. The membranes were washed once for $15 \mathrm{~min}$ in $10 \mathrm{mM}$ Tris, $150 \mathrm{mM} \mathrm{NaCl}, 0.1 \%$ Tween-20 (TBS-T), followed by three washes for $5 \mathrm{~min}$ each in TBS-T. Immunoreactive proteins were detected by incubation in HRP conjugated to goat anti-rabbit IgG (1:10 000; Pierce, Thermo Fisher Scientific, Rockford, IL, USA) for $1 \mathrm{~h}$ at room temperature. The membrane was washed as previously described and treated with ECL Plus Chemiluminescence Detection Reagent (Amersham Biosciences). Chemiluminescent signals were detected using the Storm 860 optical scanner (Amersham Biosciences), and the signals were analyzed using Image Quant TL software (Amersham Biosciences). The chemiluminescence signal intensity of each band was calculated using a local average background correction. In order to normalize for protein load on immunoblots comparing NAMPT protein quantities in prepubertal and adult chicken testes, membranes were reprobed using mouse anti- $\beta$-actin (ACTB) antibody (1:4000 Sigma-Aldrich), followed by incubation in HRP conjugated to goat anti-mouse $\lg G$ (1:10 000; Pierce), and the chemiluminescence signal was determined as previously described. NAMPT protein quantity was expressed as a proportion of $\mathrm{ACTB}$, and the relative amounts of testicular NAMPT protein were then compared.

\section{Detection of NAMPT in seminal plasma and sperm protein extract by western blotting}

Approximately $250-500 \mu \mathrm{l}$ of semen was collected through manual massage from each breeder male chicken $(n=3)$ as a single ejaculate and kept on ice. Sperm motility was confirmed by microscopic examination. Semen from each animal was centrifuged at $600 \mathrm{~g}$ for $20 \mathrm{~min}$ at $4{ }^{\circ} \mathrm{C}$, and the seminal plasma was recovered. The resultant sperm pellet was centrifuged one more time to remove residual seminal plasma. The sperm pellet was resuspended in $500 \mu \mathrm{l}$ RIPA lysis buffer containing protease inhibitor cocktail and phosphatase inhibitor cocktail 2 (Sigma-Aldrich). Protein from the sperm pellet was extracted as described above. Protein concentration of the seminal plasma and sperm protein extract were determined by protein dye-binding assay. Twenty microgram of seminal plasma or sperm protein was subjected to electrophoresis and western blotting for detection of NAMPT as described above.

\section{Quantification of plasma NAMPT levels in prepubertal and adult chickens}

Blood samples from prepubertal (4- and 14-week-old) and adult (29-week-old) chickens ( $n=7$ /age group) were collected from the wing vein into syringes coated with $10 \%$ EDTA. Blood samples were centrifuged at $1500 \mathrm{~g}$ for $15 \mathrm{~min}$ at $4{ }^{\circ} \mathrm{C}$, and plasma was collected and stored at $-80^{\circ} \mathrm{C}$ until further analysis. Plasma NAMPT concentrations were determined using a human NAMPT (COOH-terminal) enzyme immunoassay kit (Phoenix Pharmaceuticals), which had been previously 
validated for quantifying plasma NAMPT levels in chickens (Krzysik-Walker et al. 2008). All samples were run in triplicate, with sample comparisons run in the same assay to eliminate between assay variation.

\section{Statistical analyses}

All analyses were carried out by ANOVA using the general linear model procedure of the Statistical analysis system (SAS Institute, Cary, NC, USA). Differences between individual means were partitioned by Tukey's pairwise comparisons analysis in SAS. For analysis of real-time quantitative PCR data, relative NAMPT mRNA quantity to $18 \mathrm{~S}$ mRNA quantity was first converted from log-linear to linear terms. All data are represented as mean \pm S.E.M. A probability level of $P<0.05$ was considered statistically significant. Results are presented as arithmetic means \pm s.E.M.

\section{Declaration of interest}

The authors declare that there is no conflict of interest that could be perceived as prejudicing the impartiality of the research reported.

\section{Funding}

This project was supported in part by National Research Initiative Competitive Grant no. 2007-35206-17905 from the USDA Cooperative State Research, Education, and Extension Service to R Ramachandran. The microscopy unit is funded, in part, under a grant from the Pennsylvania Department of Health using Tobacco Settlement Funds.

\section{Acknowledgements}

The authors wish to thank Dr Jon Oatley, Department of Dairy and Animal Science, The Pennsylvania State University, for his valuable comments on the testis histology data. The authors also would like to thank Mr Mark Martin, Longnecker Hatcheries for providing animals. Microscopy was done at the Center for Quantitative Cell Analysis at the Huck Institutes of the Life Sciences, the Pennsylvania State University.

\section{References}

Adya R, Tan BK, Punn A, Chen J \& Randeva HS 2008 Visfatin induces human endothelial VEGF and MMP-2/9 production via MAPK and PI3K/Akt signalling pathways: novel insights into visfatin-induced angiogenesis. Cardiovascular Research 78 356-365.

Bae SK, Kim SR, Kim JG, Kim JY, Koo TH, Jang HO, Yun I, Yoo MA \& Bae MK 2006 Hypoxic induction of human visfatin gene is directly mediated by hypoxia-inducible factor-1. FEBS Letters $\mathbf{5 8 0}$ 4105-4113.

Billington RA, Travelli C, Ercolano E, Galli U, Blasi Roman C, Grolla AA, Canonico PL, Condorelli FA \& Genazzani AA 2008 Characterization of NAD uptake in mammalian cells. Journal of Biological Chemistry 283 6367-6374.

Bradford MM 1976 A rapid and sensitive method for the quantitation of microgram quantities of protein utilizing the principle of protein-dye binding. Analytical Biochemistry 72 248-254.
Brentano F, Schorr O, Ospelt C, Stanczyk J, Gay RE, Gay S \& Kyburz D 2007 Pre-B cell colony-enhancing factor/visfatin, a new marker of inflammation in rheumatoid arthritis with proinflammatory and matrixdegrading activities. Arthritis and Rheumatism 56 2829-2839.

Chan TF, Chen YL, Chen HH, Lee CH, Jong SB \& Tsai EM 2007 Increased plasma visfatin concentrations in women with polycystic ovary syndrome. Fertility and Sterility $\mathbf{8 8}$ 401-405.

Chen MP, Chung FM, Chang DM, Tsai JC, Huang HF, Shin SJ \& Lee YJ 2006 Elevated plasma level of visfatin/pre-B cell colony-enhancing factor in patients with type 2 diabetes mellitus. Journal of Clinical Endocrinology and Metabolism 91 295-299.

Chen H, Xia T, Zhou L, Chen X, Gan L, Yao W, Peng Y \& Yang Z 2007 Gene organization, alternate splicing and expression pattern of porcine visfatin gene. Domestic Animal Endocrinology 32 235-245.

Coussens M, Maresh JG, Yanagimachi R, Maeda G \& Allsopp R 2008 Sirt1 deficiency attenuates spermatogenesis and germ cell function. PLOS ONE 3 e1571.

Dietrich LS, Fuller L, Yero IL \& Martinez L 1966 Nicotinamide mononucleotide pyrophosphorylase activity in animal tissues. Journal of Biological Chemistry 241 188-191.

Haider DG, Schindler K, Schaller G, Prager G, Wolzt M \& Ludvik B 2006 Increased plasma visfatin concentrations in morbidly obese subjects are reduced after gastric banding. Journal of Clinical Endocrinology and Metabolism 91 1578-1581.

Hwang GS, Wang SW, Tseng WM, Yu CH \& Wang PS 2007 Effect of hypoxia on the release of vascular endothelial growth factor and testosterone in mouse TM3 Leydig cells. American Journal of Physiology. Endocrinology and Metabolism 292 E1763-E1769.

Kendal-Wright CE, Hubbard D \& Bryant-Greenwood GD 2008 Chronic stretching of amniotic epithelial cells increases pre-B cell colonyenhancing factor (PBEF/Visfatin) expression and protects them from apoptosis. Placenta 29 255-265.

Kitani T, Okuno S \& Fujisawa H 2003 Growth phase-dependent changes in the subcellular localization of pre-B-cell colony-enhancing factor. FEBS Letters 544 74-78.

Krzysik-Walker SM, Ocon-Grove OM, Maddineni SR, Hendricks GL III \& Ramachandran R 2008 Is visfatin an adipokine or myokine? Evidence for greater visfatin expression in skeletal muscle than visceral fat in chickens Endocrinology 149 1543-1550.

Nalbandian A, Dettin L, Dym M \& Ravindranath N 2003 Expression of vascular endothelial growth factor receptors during male germ cell differentiation in the mouse. Biology of Reproduction 69 985-994.

Nemeth E, Tashima LS, Yu Z \& Bryant-Greenwood GD 2000 Fetal membrane distention: I. Differentially expressed genes regulated by acute distention in amniotic epithelial (WISH) cells. American Journal of Obstetrics and Gynecology 182 50-59.

Ognjanovic S, Ku TL \& Bryant-Greenwood GD 2005 Pre-B-cell colonyenhancing factor is a secreted cytokine-like protein from the human amniotic epithelium. American Journal of Obstetrics and Gynecology $193273-282$.

Powanda MC, Muniz O \& Dietrich LS 1969 Studies on the mechanism of rat liver nicotinamide mononucleotide pyrophosphorylase. Biochemistry 8 1869-1873.

Revollo JR, Grimm AA \& Imai S 2004 The NAD biosynthesis pathway mediated by nicotinamide phosphoribosyltransferase regulates Sir2 activity in mammalian cells. Journal of Biological Chemistry 279 50754-50763.

Revollo JR, Korner A, Mills KF, Satoh A, Wang T, Garten A, Dasgupta B, Sasaki Y, Wolberger C, Townsend RR et al. 2007 Nampt/PBEF/Visfatin regulates insulin secretion in beta cells as a systemic NAD biosynthetic enzyme. Cell Metabolism 6 363-375.

Rongvaux A, Shea RJ, Mulks MH, Gigot D, Urbain J, Leo O \& Andris F 2002 Pre-B-cell colony-enhancing factor, whose expression is up-regulated in activated lymphocytes, is a nicotinamide phosphoribosyltransferase, a cytosolic enzyme involved in NAD biosynthesis. European Journal of Immunology 32 3225-3234.

Rudolfsson SH, Wikstrom P, Jonsson A, Collin O \& Bergh A 2004 Hormonal regulation and functional role of vascular endothelial growth factor $\mathrm{a}$ in the rat testis. Biology of Reproduction 70 340-347.

Samal B, Sun Y, Stearns G, Xie C, Suggs S \& McNiece I 1994 Cloning and characterization of the cDNA encoding a novel human pre-B-cell colony-enhancing factor. Molecular and Cellular Biology 14 1431-1437. 
Segawa K, Fukuhara A, Hosogai N, Morita K, Okuno Y, Tanaka M, Nakagawa Y, Kihara S, Funahashi T, Komuro R et al. 2006 Visfatin in adipocytes is upregulated by hypoxia through HIF1alpha-dependent mechanism. Biochemical and Biophysical Research Communications 349 875-882.

Streffer C \& Benes J 1971 Nicotinamide mononucleotide. Determination of its enzymatic formation in vitro and its physiological role for the biosynthesis of nicotinamide-adenine dinucleotide in mice. European Journal of Biochemistry 21 357-362.

Tanaka M, Nozaki M, Fukuhara A, Segawa K, Aoki N, Matsuda M, Komuro R \& Shimomura I 2007 Visfatin is released from 3T3-L1 adipocytes via a non-classical pathway. Biochemical and Biophysical Research Communications 359 194-201.

Varma V, Yao-Borengasser A, Rasouli N, Bodles AM, Phanavanh B, Lee MJ, Starks T, Kern LM, Spencer HJ III, McGehee RE Jr et al. 2007 Human visfatin expression: relationship to insulin sensitivity, intramyocellular lipids, and inflammation. Journal of Clinical Endocrinology and Metabolism 92 666-672.
Yang H, Yang T, Baur JA, Perez E, Matsui T, Carmona JJ, Lamming DW, Souza-Pinto NC, Bohr VA, Rosenzweig A et al. 2007 Nutrient-sensitive mitochondrial NAD + levels dictate cell survival. Cell 130 1095-1107.

Yilmaz MI, Saglam M, Qureshi AR, Carrero JJ, Caglar K, Eyileten T, Sonmez A, Cakir E, Oguz Y, Vural A et al. 2008 Endothelial dysfunction in type-2 diabetics with early diabetic nephropathy is associated with low circulating adiponectin. Nephrology, Dialysis, Transplantation 23 1621-1627.

Yonezawa T, Haga S, Kobayashi Y, Takahashi T \& Obara Y 2006 Visfatin is present in bovine mammary epithelial cells, lactating mammary gland and milk, and its expression is regulated by cAMP pathway. FEBS Letters $\mathbf{5 8 0} 6635-6643$.

Received 4 September 2008

First decision 5 November 2008

Revised manuscript received 10 August 2009

Accepted 4 September 2009 